\title{
Television news content of minority groups as an intergroup context indicator of differences between target-specific prejudices
}

*** Article accepted for publication in Mass Communication and Society ***

Cecil Meeusen* - Institute for Social and Political Opinion Research, Centre for Sociological Research, University of Leuven

Laura Jacobs - Centre for Citizenship and Democracy, Centre for Political Science Research, University of Leuven

*Corresponding author, Parkstraat 45, box 3601, 3000 Leuven

\section{Acknowledgements:}

The first author wishes to thank the Research Foundation Flanders (FWO) for the $\mathrm{PhD}$ fellowship, which made it possible to contribute to this article. 


\begin{abstract}
Although research has shown that different types of prejudice are highly correlated, prejudice hierarchies indicate that individuals differentiate between target groups. Here we examine the relationship between television news coverage and differences in attitudes toward minority groups. We rely on intergroup threat theory, tone and framing theories to formulate our hypotheses and conduct a multi-method study: All prime-time television news items in Flanders $(\mathrm{N}=1,487$ ) reporting on five minority groups (LGBT, Jews, Eastern Europeans, NorthAfricans, Roma) were coded in terms of tone and framing, and subsequently combined with individual-level survey data. Patterns in news coverage reflect differences in prejudice: groups that are most negatively/positively evaluated by the public receive the most negative/positive coverage. Prejudice is especially high for minority groups associated with problems and criminal threat frames in the news. We conclude that news content is an important characteristic of the intergroup context reflecting differences in minority group appraisals in society.
\end{abstract}

Key words: Media, Target-specific prejudice, Tone \& Framing theory, Intergroup Threat Theory 


\section{Introduction}

Research has repeatedly shown that target-specific prejudices, defined as negative attitudes directed at a specific target group, are highly associated: individuals who dislike one target group (e.g. immigrants) are likely to dislike other target groups (e.g. homosexuals, Jews) as well, even though these groups are dissimilar (Zick et al. 2008). This consistency in targetspecific prejudices is conceptualized as 'generalized prejudice' and ascribed to authoritarian and competitive personality traits (Allport 1954; Duckitt 1992). Empirical research has highlighted, however, that beyond overall levels of generalized prejudice across groups, individuals also differentiate between target groups (Meeusen and Kern 2016). This suggest that there are triggers outside of one's personality that make individuals more prone to certain types of prejudice compared to others. Previous research has almost exclusively focused on the origins of either generalized prejudice or a single target-specific prejudice. In this study, we combine both perspectives by investigating why individuals differentiate between groups, while taking into account their overall tendency to (dis)like outgroups in general.

The limited research on the topic suggests that characteristics idiosyncratic to the target group, or the 'intergroup context', explain why individuals distinguish between target groups (Zick et al., 2008), but this proposition has never been directly addressed. In this study, we argue that the news environment is a crucial aspect of the intergroup context and can cultivate views on various groups in society. The impersonal impact hypothesis asserts that lack of direct contact experience with target groups stimulates individuals to rely on indirect information sources, such as television news, to form societal judgements (Shrum and Bischak, 2001). Hence, news depictions of certain target groups can shape how individuals evaluate groups and why people differentiate between groups. Media studies have consistently shown, however, that negative news portrayals of minority groups are widespread (Ter Wal et al., 2005) and that recurrent exposure to these messages can cultivate threat perceptions and prejudice (Atwell Seate and Mastro, 2016; Boomgaarden and Vliegenthart, 2009; Van der Linden \& Jacobs, forthcoming). In this regard, especially the importance of theories on news tone and framing of groups has been emphasized (Bleich et al., 2015). Tone is conceptualized as the positive or negative evaluative consideration for groups in the news, while framing relates to how specific groups are being portrayed and which aspects are being emphasized.

Most prior studies, however, have adopted a non-differentiated, one-size-fits-all approach focusing on one single group (often immigrants or racial groups such as Latinos or African- 
Americans) without systematically comparing news portrayals of different target groups. In this study, adopting a media-based approach, our explicit aim is to fill this void in the literature. Our research question reads as follows: are differences in tone and framing in news coverage on various target groups related to differences in feelings of prejudice toward these groups? The main contribution to the literature is that we consider news media not only as a factor closely related to prejudice, but also as a characteristic of the intergroup context, potentially differentiating between target-specific prejudices. To answer the research question we rely on a multi-method design. First, we systematically and longitudinally investigate portrayals on primetime television news (2003-2014) in Flanders (Dutch-speaking region of Belgium) of five salient minority groups in the Belgian intergroup context $(\mathrm{N}=1,487)$ : North-Africans, Eastern Europeans, LGBT, Jews and Roma. More specifically, the dominant tone and the occurrence of threat frames are investigated. Second, we combine this content analysis with survey data on how the majority group, here Flemish natives, evaluate these five minority groups.

Our multi-method design adds to the literature in four significant ways. First, while most studies have focused on newspapers, we consider television news. Typically television news is an easily accessible medium, attracting large and diverse audiences (Morgan and Shanahan, 2010). Recent figures show that television newscasts in Europe are the 'main' information source about political issues, rendering television a large potential to shape public opinion (Eurobarometer, 2012). Second, while past studies have relied on small samples of several weeks, we use a dataset covering every reference to the five groups on television news from 2003 until 2014, filtering out the impact of coincidental variation. Moreover, twelve years of news content presents us with a sufficiently large sample size for in-depth comparison of news content for various minority groups, in contrast to the undifferentiated approach of many prior studies. Furthermore, due to the longitudinal approach we can assess whether portrayals for different minority groups are stable and consistent over time. Twelve years of television coverage bring along a large socialization potential. As such news content can be considered as an information environment, as a characteristic of the intergroup context in which attitudes are developed (Boomgaarden and Vliegenthart, 2009). Third, although research has suggested that not exposure but rather specific news content is related to prejudice, studies on news coverage and prejudice often rely on self-reported news exposure without actual news content data (Schuck et al., 2015). To address this shortcoming, we analyse television news coverage in Flanders and link it directly to Flemish survey data including feeling thermometers on the five minority groups. Fourth, we take into account that target-specific prejudices are highly 
associated and decompose the generalized and target-specific components of prejudice, thereby offering a comprehensive account of the relationship between news and the different components of prejudice.

\section{News Coverage and Prejudice}

Most contemporary definitions of prejudice still rely on the traditional conceptualization by Allport (1954: 9) who defined prejudice as 'a hostile attitude toward a person who belongs to a group, simply because he belongs to that group, and is therefore presumed to have the objectionable qualities ascribed to the group'. In that sense, prejudiced feelings often serve to legitimize inequality and even justify discrimination (Crandall and Eshleman 2003). Allport observed that individuals are highly consistent in their prejudiced beliefs and hold a general tendency to devalue any kind of group considered to be different from the own group, which he called 'generalized prejudice'. Duckitt (1992) emphasized that although individuals indeed have a generalized prejudice inclination, they do not evaluate all target groups equally: some groups are evaluated more negatively or positively than others, resulting in prejudice hierarchies (Hagendoorn, 1995). This implies that there are target-specific motives fuelled by factors outside of one's personality explaining why individuals differentiate between groups. Intergroup literature suggests that perceived group characteristics (e.g. socio-economic status), situational (e.g. intergroup contact), societal factors (e.g. policy, economic development), or intergroup context indicators (e.g. neighbourhood diversity, news portrayals of minority groups) contribute to this differentiation between prejudices (Havekes et al., 2011; Meeusen and Kern, 2016). Lubbers et al. (1998: 418) contributed to this debate by suggesting that news exposure presents a crucial aspect of this intergroup context and as such might 'construct a picture of differences between groups'.

Members of the dominant majority group do not often enter in direct contact with minority members and therefore often rely on other indirect information sources, such as news, to shape their opinion about minorities. The impersonal impact hypothesis suggests that news coverage is especially relevant in shaping societal-level attitudes such as outgroup evaluations (Shrum and Bischak, 2001). Therefore, news depictions of target groups, especially if they prove to be stable and consistent over time by showing a uniform picture as suggested by cultivation studies (Morgan and Shanahan, 2010), can be considered an important characteristic of the intergroup context in which intergroup attitudes are shaped. Overall, content analysis of news depictions 
of ethnic minorities shows that they tend to be predominantly covered from a negative angle (Ter Wal et al., 2005). A well-documented phenomenon by media effect studies is that exposure to negative, stereotypical and problematizing news depictions of minorities and immigrants can perpetuate negative attitudes in society ${ }^{1}$ (Boomgaarden and Vliegenthart, 2009; Schlueter and Davidov, 2013; Schemer, 2014).

In addition -and this is a largely understudied topic- news depictions may also relate to hierarchies in prejudice. News media may emphasize (un)favourable characteristics depending on the target group, thereby promoting/reflecting differences in intergroup evaluations. Via content analysis of Dutch newspapers, Lubbers et al. (1998) explicitly tested whether a similar ethnic hierarchy was present among public opinion and in news messages: natives were less willing to interact with ethnic minorities that were systematically problematized in news coverage. Persistent associations of groups with problems may foster feelings of threat, which -due to processes of causal attribution- may result in harsher evaluations of these groups. In sum, if news differentiates in reports on minority groups, the audience may pick up this disparity, resulting in target-specific evaluations. The tone and framing of target groups in the news can closely relate to interpretations of issues and attitudes (Bleich et al., 2015). In this article, we rely on tone and framing theory to assess how differences in news coverage for the various target groups relate to target-specific prejudices.

\section{News tone}

The tone or general direction (positive or negative) of news items is considered important because it adds an affective component to news stories (Sheafer, 2007). Research has emphasized that the evaluative tone of news plays a large role for the salience and interpretation of political issues (Balmas and Sheafer, 2010). News stories can activate certain evaluations

\footnotetext{
${ }^{1}$ It should be noted here, however, that media and public opinion are interdependent: public opinion may steer news content as well. While there is tentative evidence that news consumption impacts attitudes toward minorities (Boomgaarden and Vliegenthart, 2009; Schlueter and Davidov, 2013), past research has stressed that news may simply reflect public opinion (Zhou and Moy 2007). Similarly, current research is still inconclusive about the role of self-selection mechanisms, i.e. the tendency of individuals to consume content which is perceived to reflect prior beliefs (Oliver and Armstrong, 1995).
} 
about issues, or in this case groups, thereby possibly stimulating public opinion to align with this dominant viewpoint. The underlying idea is that information has the potential to alter public opinion in the direction of the dominant tone of news as biased information becomes very salient in citizens' minds (Zaller, 1992). Therefore, in a news environment marked by recurrent negative and problematizing narratives, these negative messages are easily accessible and have the potential to cultivate negative attitudes in society. Hence, positive and negative stories on minorities are thus anticipated to impact intergroup evaluations. Overall, prior studies have found some support that the role of news tone indeed matters when evaluating ethnic minorities or immigrants (Schlueter and Davidov, 2013; Schemer 2014; Boomgaarden and Vliegenthart, 2009; Van Klingeren et al., 2015): exposure to a negative news story increased negative attitudes, while exposure to positive examples fostered tolerance.

The current study takes these prior conclusions about the role of news tone as a starting point by extending insights whether divergence of tone in television news on different minorities (e.g. minorities that are being depicted more positively or negatively than others) relates to differences in prejudice. Building on theories stressing the importance of news tone, we formulate the following two hypotheses: The more often a minority group is portrayed in positive $(\mathrm{H} 1)$ / negative $(\mathrm{H} 2)$ news items, the more positive $(\mathrm{H} 1)$ / negative $(\mathrm{H} 2)$ the feelings toward that minority group.

\section{News framing: The role of threat}

News framing refers to how issues, or in this case groups, are presented in the news. Frames are 'central organizing ideas' that give meaningful insights to an issue; framing implies that certain aspects of a news story are being emphasized, favouring some interpretations over others (De Vreese, 2005; Scheufele and Tewksbury, 2007). News reports on groups and by doing so they highlight specific arguments and offer interpretations, thereby promoting a specific vision (Gamson and Modigliani, 1989). As Entman (1993) notes in his pioneering work, frames can be instrumental in stimulating certain problem definitions, cause diagnoses, moral judgements and remediation strategies. The way news stories on minority groups are being framed has been the focus of a large number of studies (e.g. Fryberg et al., 2012; Kim et al., 2011; Van Gorp, 2005; Roggeband and Vliegenthart, 2007). Overall, conclusions are that frames are omnipresent in news coverage and that news coverage stimulates specific interpretations. More specifically, one recurrent finding is that ethnic minorities and immigrants are portrayed as posing threats to 
society by challenging dominant cultural values, economic benefits and safety (Atwell Seate and Mastro, 2016; Van Gorp, 2005; Watson and Riffe, 2012).

Following the integrated process model of framing (De Vreese, 2005) and building on prior studies on news framing of outgroups as posing threats to society (Atwell Seate and Mastro, 2016; Van Gorp, 2005), we deductively construct issue-specific news frames based on intergroup threat theory, i.e. one of the main guiding theories in intergroup relations. In line with Entman's definition, threats entail a specific vision of a problem and who is to blame for this problem, making framing an excellent theory guiding this study. Intergroup threat occurs 'when one group's actions, beliefs, or characteristics challenge the goal attainment or wellbeing of another group' and is highly functional in justifying and motivating prejudice (Riek et al., 2006). Economic, cultural and criminal sources of threat are identified. Socio-economic threat refers to material competition between groups over scarce goods (e.g. housing, jobs and welfare). Minorities are perceived as undermining the economy and as less deserving of social support. Cultural threat refers to threat perceptions due to the perceived incompatibility of cultures, religions, norms and values. Further, feelings of threat can be prompted by insecurity and fear caused by the perceived overrepresentation of minorities in criminal activities.

Building on intergroup threat theory, we distinguish three types of threat frames -cultural, economic and criminal- to investigate which frames are used for different minority groups, how they relate to prejudice and which type of threat is decisive. Prior research by Lubbers et al. (1998) emphasized the importance of criminalization processes in news while explaining ethnic hierarchies. There are indeed reasons to expect that especially criminal threat frames play a powerful role in this regard. Crime presents a very important element of news coverage of ethnic minorities and immigrants, which are overrepresented as perpetrators of, mostly violent, crime (Dixon and Linz, 2000; Jacobs, forthcoming). References to crime can be considered more blatant expressions of prejudice (Pettigrew and Meertens, 1995) and are more likely to be unambiguously negative (Zaller, 1992) because of their focus on social disorder and problems. Moreover, crime stories are typically framed episodically, highlighting concrete events and ignoring context, thereby attributing responsibility to individuals, which holds less for other topics (Iyengar, 1991). Crime also presents a more suitable topic for television due to its sensational and emotional nature (Uribe and Gunter, 2007). This all suggests that criminal threat frames on television may be more decisive for attitudinal differences between minority groups than economic and cultural threat frames. Based on intergroup threat theory and the integrated process model of framing, we formulate our third hypothesis: The more often a minority group 
is portrayed in news items with a criminal threat frame, as compared to an economic or cultural threat frame, the more negative the feelings toward that minority group (H3).

\section{Empirical Background: The Belgian Context}

We consider negative feelings toward five minority groups prominently present in the Belgian intergroup context. In this study, a minority group is a numeric minority with a disadvantaged and superordinate position in society compared to the majority group, here the Flemish natives. The target groups were chosen because of the salience of the group in current public and policy debates, and because we wanted to include a broad range of minority groups which are targeted for diverse reasons. First, we included three ethnic and immigrant groups: North-Africans, Eastern Europeans and Roma. Belgium has an immigration history with guest workers coming from North-Africa. Due to EU enlargement and the free movement of persons Eastern Europeans are relocating to Belgium in particular for economic purposes (OECD, 2015). These immigration flows foster feelings of threat due to competition over jobs and welfare expenditure (Hainmueller and Hiscox, 2010). Moreover, as Eastern Europeans and North-Africans share different cultural and/or religious values, immigration is also seen as a threat to the sociocultural order. Increased EU mobility has also facilitated Roma to travel between member states. While a small minority in Belgium, Roma are increasingly problematized and associated with immorality, criminal behaviour, and poor living conditions (Ljujic et al., 2012). Furthermore, as immigration is the core issue of the Flemish extreme-right party Vlaams Belang (Walgrave and De Swert, 2002), North-Africans, Eastern Europeans and Roma are often subject of elite discourse, increasing their visibility in public debate. Second, we included LGBT as an ambivalent minority group. Belgium is a pioneering country with regard to LGBT rights: it was one of the first countries to legalize same-sex marriage and adoption. While blatant expressions of homophobia are declining, implicit prejudice remains widespread and heterosexuality is still the prevailing standard (Dewaele et al., 2008). Third, Jews were included as a religious minority group. Prejudice toward Jews is characterized by envy rather than by cultural or religious threat (Fiske et al., 1999). Because of their historic position, explicit antisemitism is socially less acceptable in Belgium. Taking into account the contextualization of these five minority groups, we expect that feelings will be most positive toward LGBT and Jews, and most negative toward immigrant and ethnic minority groups. 
Belgium is a federal state in which the language groups -the Flemish, French- and Germanspeaking communities- have their distinct media system; media consumption across the linguistic border is limited (Sinardet, 2013). We focus on the media system of the Flemish community, the largest language group in Belgium. From a comparative point of view, the Flemish television landscape is not exceptional and is representative for other Western European societies: it is an example of the democratic corporatist model of media and politics, where a strong public broadcaster co-exists with commercial players in a fragmented television market (Hallin and Mancini, 2004).

\section{Data and methods}

\section{Content analysis}

Sample. We rely on 1,487 television news items reporting about the five minority groups on the prime-time newscasts (i.e. daily at $7 \mathrm{pm}$ ) of the two main Flemish television stations from January 2003 until May 2014 (Election day, see survey data). These news items were obtained from the Electronic News Archive (ENA), a large-scale digital news archive commissioned by the Flemish government which is publicly available for scientific research. Since 2003, every prime-time newscast of the public broadcaster VRT and of the main commercial broadcaster VTM is archived, coded and analysed on a daily basis. Inter-coder reliability tests are carried out on a regular basis, showing codings are satisfactory (De Smedt et al., 2013). These broadcasters are the two main players on the Flemish television market. ${ }^{2}$ In 2014, 'Het Journaal' on VRT reached a market share of $52.6 \%$, while 'Het Nieuws' on VTM reached a market share of $42.8 \%$. No other Flemish newscast comes near this market share. Together they reach the majority of news viewers in Flanders (CIM TV, 2014). Importantly, we do not rely

\footnotetext{
${ }^{2}$ Both broadcasters diverge in terms of goal attainment, as the partly state-funded public broadcaster is expected to deliver a service to the citizens (Jacobs, Meeusen, \& D’Haenens, forthcoming). Moreover, they have signed a Diversity charter institutionalizing their objective to report on minorities in an equitable and inclusive manner, while commercial broadcasters do not have similar obligations. There are small differences as reporting is slightly less negative on the public broadcaster and contains less references to threat, but overall patterns are very similar: we observe the same ranking for the five outgroups.
} 
on a sample, but study the entire population of news stories in which the five outgroups were featured during a twelve-year period.

The selected period (2003-2014) entails two methodological advantages: first, including twelve years of news content allows for a sufficient sample size to study news coverage for underrepresented groups, such as Roma. Relying on a limited sample would greatly reduce the number of cases, rendering reliable conclusions about patterns in news depiction of these minority groups impossible. Second, the broad range of societal developments and events in this period with regard to minorities permits sufficient variation in news content.

For each news item the headline or general description (as read by the news anchor) and several keywords describing the item were recorded. To select all news coverage of the five minority groups, we developed a string of relevant search terms. These search terms differed for each minority group and were meant to capture explicit references to these groups. They included various terms, which are used to refer to the group as well as synonyms and derived words. For North-Africans, for instance, search terms were 'North Africa' and 'NorthAfricans', supplemented with terms aimed at capturing specific North African countries, origins and nationalities (e.g. Morocco, Maghreb, Berber, Algerian). Full search strings are available from the authors upon request. Using this strategy, all news items mentioning the minority group in either headline/description or keywords were manually selected, resulting in a sample of 1,487 news items (138 Roma; 268 North-Africans; 277 Jews; 327 LGBT; 477 Eastern Europeans). We only included domestic news as we agree with ter Wal et al. (2005) that the operationalization of a minority group is context-specific. Domestic news is defined as any event, situation or story involving minorities within the Belgian setting, with a focus on internal affairs.

Coding and inter-coder reliability. The coding was conducted by the authors of this study. During the training period several test items were independently coded. Codings for the variables were compared to identify discrepancies. Ambiguous news items were closely analysed by watching the news item together and through discussion a joint decision was reached. Inter-coder reliability was evaluated by double-coding almost $10 \%$ of the news items. Krippendorff's Alpha values for all variables were satisfactory with an average of .80 (Krippendorff, 2013).

Variables. Television in Flanders is organized in several news items or segments of news stories of 1 to 2 minutes in length, and these present the unit of analysis. This means that all 
audiovisual information in the news item was used to make an assessment for the tone and threat frame variables for the specific outgroup. Two sets of television news content variables were coded (examples in Appendix A): tone and threat frames. The tone was conceptualized as the direction of news items. A key question in this regard relates to whether minorities are portrayed in a favourable manner or not. Building on prior examples (Boomgaarden \& Vliegenthart, 2009; Van Klingeren et al., 2015; Schemer, 2014), a negative tone relates to news stories which focus on negative consequences or aspects linked to outgroups, while a positive tone relates to news stories which focus on positive consequences of outgroups. For instance, whenever a news story focuses on increasing crime levels, rising social expenditure following immigration, or cultural tensions, this is considered to be 'negative' in tone; whenever, a news story focuses on safety, wealth creation or enrichment of a culture by diversity, this is considered to be 'positive' in tone. Tone was coded using the following question: 'Overall, would you say the news item has a positive, negative, mixed or neutral tone?' (Van Klingeren et al., 2014). In addition, following Lubbers et al. (1998), we distinguished between negative news items dealing with problems caused by the minority group and problems not caused by the minority group. An example may clarify this: a crime story is coded as 'negative', but the negativity is not necessarily caused by the minority group member if s/he is the victim. We aim to correct for this nuance as it is relevant to know whether pure association with a negative story is enough to induce prejudice, or whether causal attribution is a precondition. Tone was included as percentage of the total news coverage for the minority group on the newscast. Following variables were created for each group: $\%$ negative news, $\%$ positive news, $\%$ minority group is cause of the problem.

We also developed economic, cultural and criminal threat frames. We relied on Entman's operationalisation of problem definitions of framing: we first coded whether a news item dealt with criminal, economic or cultural issues. It was possible that more frames were applicable to one news story. Second, we coded whether the news reported on a problem and whether minorities were attributed responsibility for this problem or not. Threat frames are the combination of a criminal, economic or cultural frame with a problem presented as caused by the minority group. They were included as percentages of the total news coverage for the minority group: \% criminal threat frame, $\%$ cultural threat frame and $\%$ economic threat frame. 


\section{Survey data}

Sample. The survey data that are linked to the content analysis stem from the Belgian Election Panel 2009-2014 (BEP, Dassonneville et al., 2014). Attitudes toward minority groups were measured in 2014, as part of a pre-election survey (March 25-May 25). In 2014, the full 2009 address-sample was updated so that 4,448 respondents could be re-contacted for participation. After three reminders, 1,542 (or 34.4\%) valid surveys were returned. Respondents were Belgian residents who were at least 18-years old. For this study, only the Flemish subsample was used $(\mathrm{N}=847)$. Unfortunately, due to ethical reasons, no information on ethnic background or sexual orientation was registered, making that we could not exclude citizens with another ethnic background and sexual minorities from the sample. Consequently, the Flemish majority sample also includes some minority respondents, a limitation of the survey.

Variables. Positive feelings toward minority groups were measured with feeling thermometers. Respondents were asked to rate the five minority groups on a 0 to 100 scale, with higher values indicating more positive feelings. Because of their standardized and neutral nature, feeling thermometers permit comparability between the groups. Next, to avoid spurious effects, control variables linked with prejudice and news consumption were included: gender (49.4\% male), education level (6-point scale, 1 = 'no degree', 6 = 'university degree', $M=4.19$, $\mathrm{SD}=1.15)$, age (range 23-94, $\mathrm{M}=54.70, \mathrm{SD}=16.27)$, left-right ideology ( 0 = 'left', $10=$ 'right', $\mathrm{M}=5.32, \mathrm{SD}=2.27$ ), frequency of television news consumption (6-point scale, $1=$ 'never', $6=$ 'daily', $\mathrm{M}=4.94, \mathrm{SD}=1.47$ ), and frequency of other news consumption (newspaper, news sites, and radio news, 6-point scale, $1=$ 'never', $6=$ 'daily', $\mathrm{M}=4.10, \mathrm{SD}=$ $1.24){ }^{3}$

\section{Method}

To link the news content with the individual-level survey data, the data file was restructured into a two-level multivariate design (Hox, 2010). This model is used to analyse variation between the multiple outcome variables -here the five target-specific thermometer ratingsgiven by the same respondent. This way, the feeling thermometer ratings (level 1) are nested within individuals (level 2) (for a graphical representation of the design see Figure 1). At level 2 , the between-individual component refers to differences between individuals in negative

\footnotetext{
${ }^{3}$ Results were similar if news media consumption of radio, newspaper and website were considered separately (i.e. all parameters were non-significant). For reasons of parsimony, we included them as a sum-scale.
} 
feelings averaged across all minority groups (i.e. generalized prejudice). At level 1, the withinindividual component refers to differences between the five minority groups in negative feelings within the same respondent. By consequence, at the within-individual level the dependent variable refers to 'target-specific positive feelings' and the variance represents differences between the target group ratings. At the between-individual level the dependent variable captures 'general positive feelings across target group' and the variance represents differences between individuals. The television news content indicators are target-specific (and thus vary within respondents) and therefore entered at level 1; the control variables are respondent-specific and are therefore entered at level 2 (for overview of variables in the multilevel design see Figure1 and Appendix B).

Similar to Hopmann et al. (2010) and Schemer (2014) television news content indicators were matched with respondents depending on the specific television news broadcaster the respondent watches. In an open question, respondents indicated which television newscast they had watched most often during the last two weeks $(\mathrm{N}=27$ missing): $4.1 \%$ of respondents had not watched any television news, $61.5 \%$ public news, $21.7 \%$ commercial news, $5.9 \%$ both public and commercial news, and $3.7 \%$ other news broadcasters. If a respondent indicated to watch public/commercial news, s/he was matched with the news content indicators of public/commercial news for each minority group. A respondent who watched both commercial and public news was assigned the average of the news content indicators of both broadcasts. Respondents who watched other broadcasters or who did not watch television news were not included in the analyses as there were no media data to match $(\mathrm{N}=62)$ (Hopmann et al., 2010), resulting in a sample of $\mathrm{N}=758$.

An example may further clarify the design: Respondent 1 in Appendix B is a woman who indicated to watch public news. She has rated the five minority groups on a 0-100 scale. The goal is to assess whether the differences the woman makes in rating the five groups are related to the differences in news content for the various groups she was exposed to. Therefore, for each minority group, the television news indicators of public news were matched with the target-specific ratings of the respondent (e.g. $7.3 \%$ of the news items on Jews had a positive tone on public news).

In multilevel language this model can be written as: $Y_{i j}=\gamma_{00}+\gamma_{10} X_{i j}+\gamma_{01} Z_{j}+\mu_{0 j}+e_{i j}$; where the dependent variable $\mathrm{Y}_{\mathrm{ij}}$ represents the rating of target group i (e.g. Jews) of respondent j. The score on this dependent variable is a function of the average positive feeling (for all 
respondents) across the target-groups $\gamma_{00}$, the effect $\gamma_{10}$ of the media content indicator $X$ (e.g. $\%$ positive tone), the effect $\gamma_{01}$ of the respondent-specific indicator $Z$ (e.g. gender) and two error components for level $1\left(\mathrm{e}_{\mathrm{ij}}\right)$ and level $2\left(\mu_{0 \mathrm{j}}\right)$.

In sum, multilevel modelling was chosen (1) because this design makes it possible to link our news content data with the public opinion data, (2) because of the nested structure of the data, that is, target group ratings nested within individuals, and (3) because this design allows controlling for background variables such as gender, education, news consumption and generalized prejudice. To avoid multicollinearity, the news content variables were tested in separate models. To correct for the slight underrepresentation of the low-educated and women, weights were applied. All continuous variables were grand mean centred. Missing data were handled with multiple imputation in Mplus 7.3. 
Figure 1 - Design of the multilevel structure

Level 2: Differences in general positive feelings BETWEEN individuals

Independent variables:

Gender

Education level

Age

Left-right ideology

Frequency of television news consumption

Frequency of other news consumption

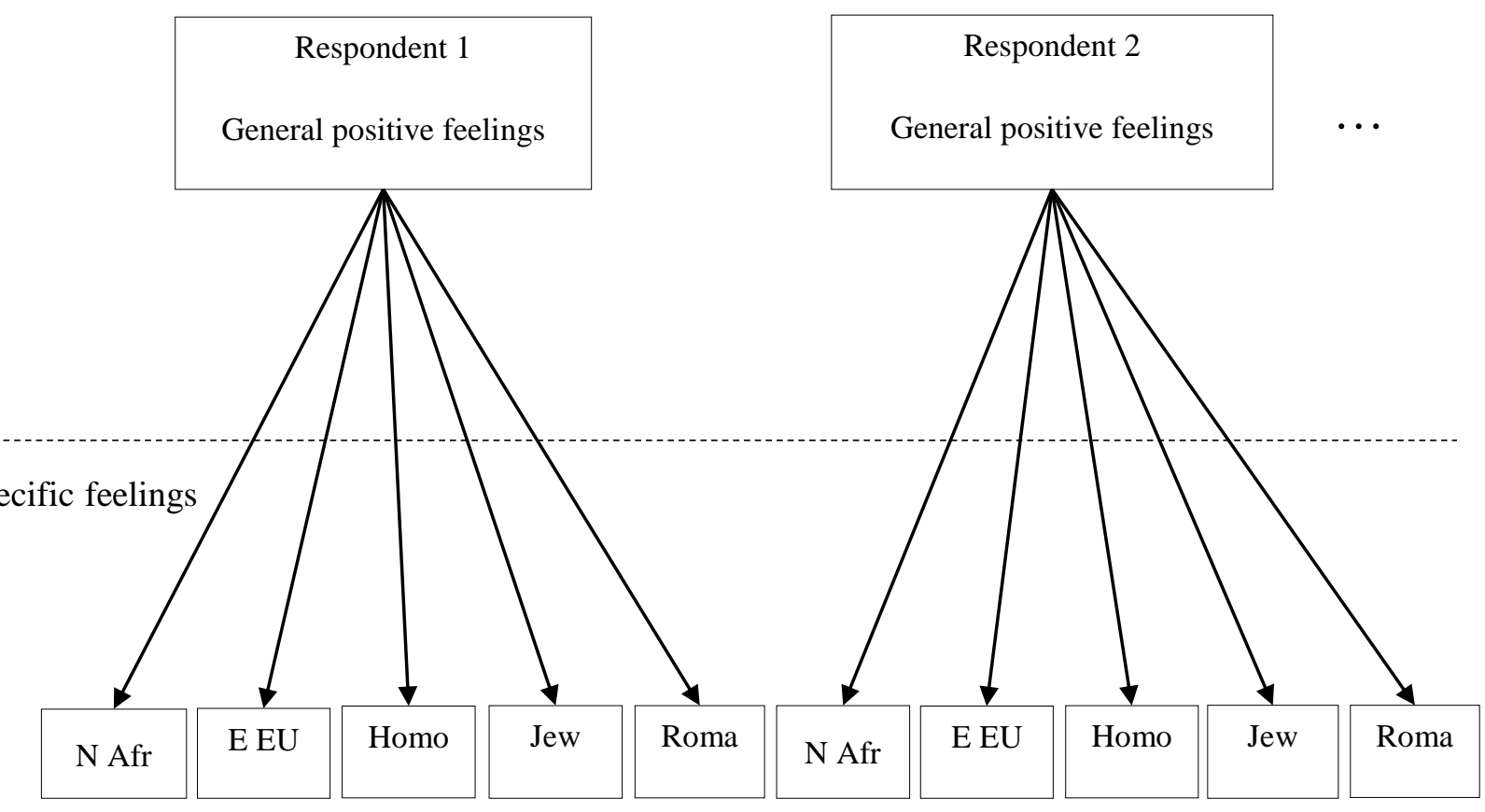

in news

$\%$ criminal threat frame

$\%$ economic threat frame

$\%$ cultural threat frame

Target-specific prejudice toward 


\section{Results}

We start the analysis by ascertaining whether there is evidence of a hierarchy in prejudice across the respondents. The Flemish public indeed differentiates between minority groups: on average, attitudes are most favourable toward LGBT, followed by Jews; North-Africans and Eastern Europeans are rated equally negative; Roma are most disliked (Figure 2). This hierarchy was similar for people who reported to watch public news or commercial news. ${ }^{4}$

Figure 2 - Average levels of positive feelings toward minority group

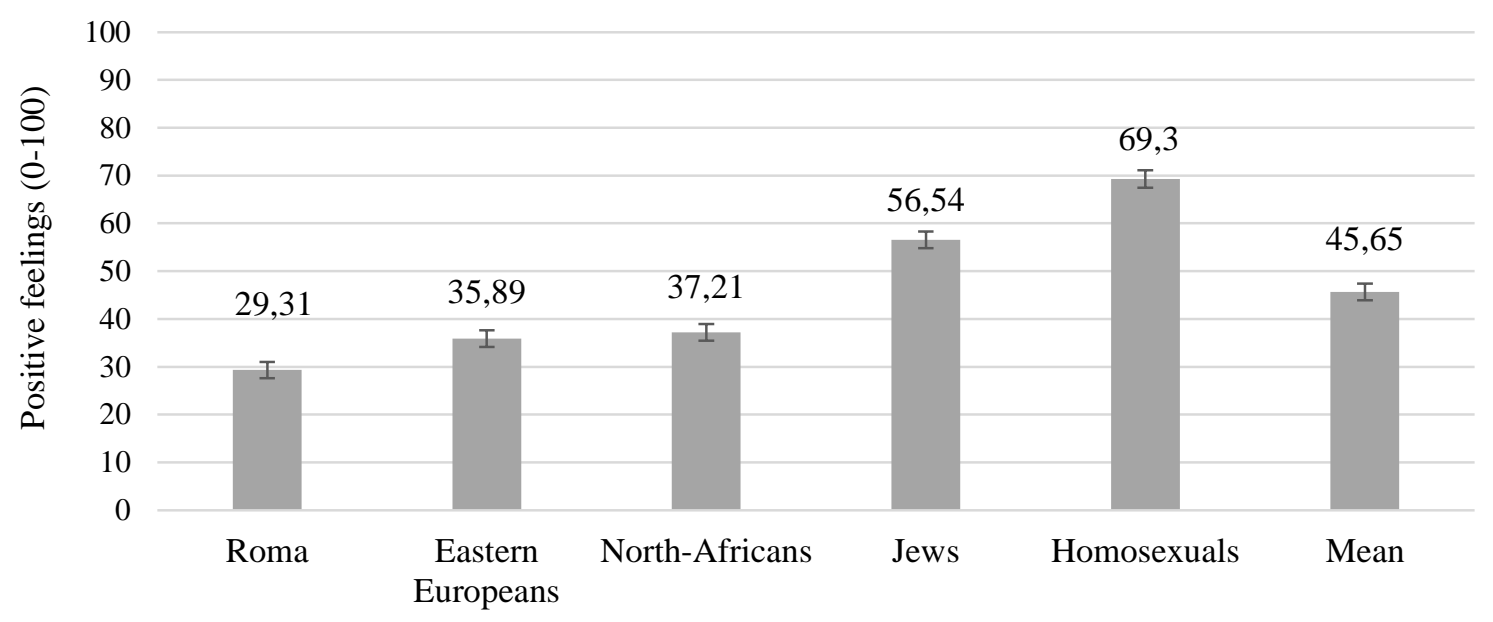

\footnotetext{
${ }^{4}$ On the one hand, individuals who did not watch any news were less positive toward North-Africans, Eastern Europeans, and Roma compared to individual who watched television news. On the other hand, individuals who did not watch any news were more tolerant toward Jews and homosexuals compared to individuals who watched television news.
} 
Figure 3 compares the media tone for the groups. Only $7.8 \%$ of the news stories have a positive tone. LGBT receive the most positive news coverage, although even here only $14.5 \%$ of the news stories is positive. The evidence thus points to a negativity bias in television news on minority groups. This negativity bias is, however, group-specific: news items on Roma, North-Africans and Eastern Europeans more often have a negative tone than news on LGBT. We also find that ethnic minority groups are often depicted as cause of the problem in negative news stories. LGBT and especially Jews are often portrayed in negative news stories as well, but they are rarely depicted as cause of the problem. Roma receive the most negative news coverage. Moreover, assessing trends over time reveals that these differences in tone are quite stable: LGBT always receive the least negative and the most positive news coverage, whereas especially North-Africans, Roma and Eastern Europeans are depicted in negative news items and as cause of the problem. Jews, are always depicted with a negative tone, but are -like LGBT- far less often portrayed as being responsible for a problem. ${ }^{5}$

\footnotetext{
${ }^{5}$ Detailed figures showing trends over time are available from the authors upon request.
} 
Figure 3 - News tone for minority groups on prime-time television news 2003-2014

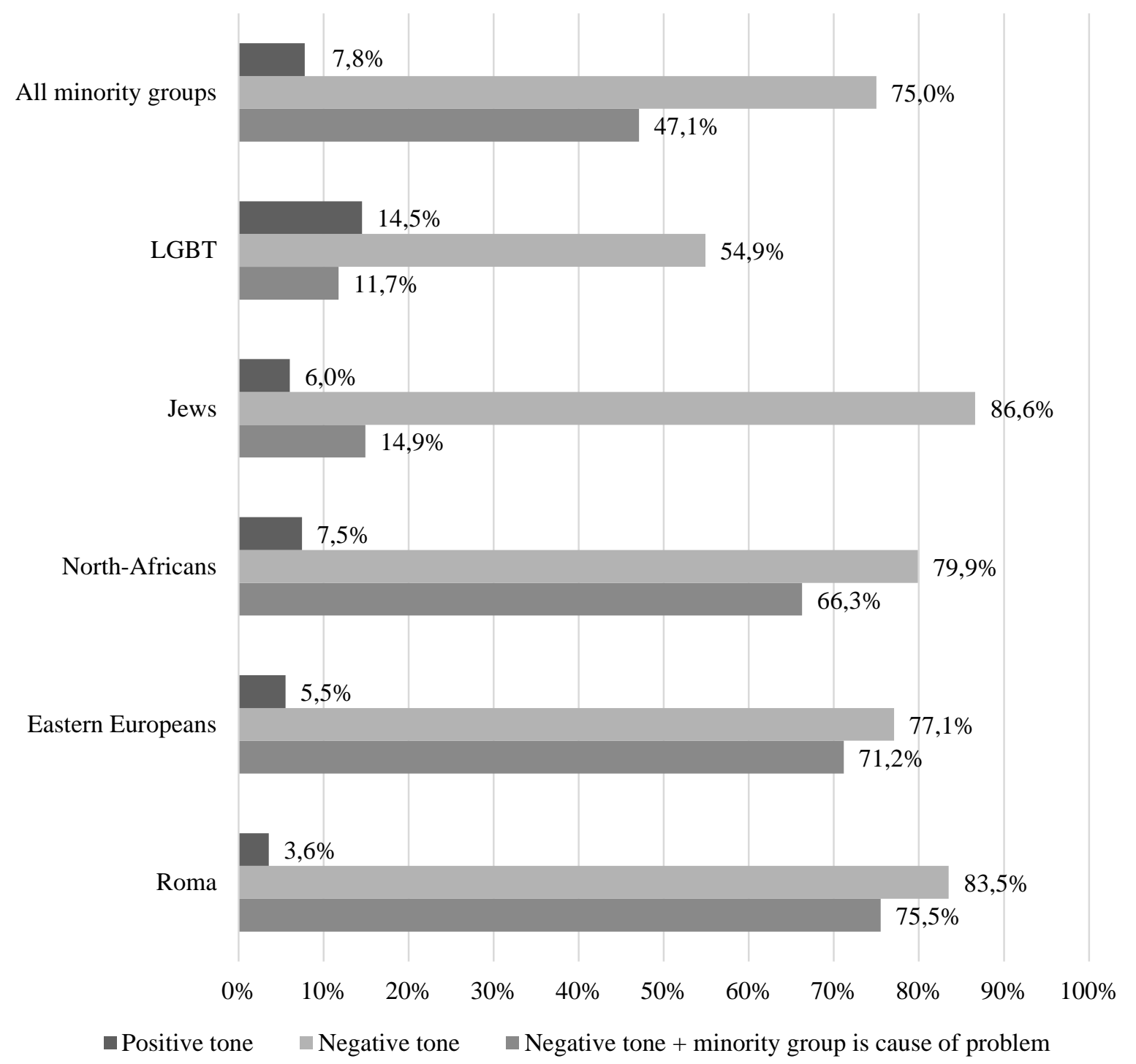

Note. Entries are percentages for news tone relative to the number of total television news stories about the minority group on the newscast (2003-2014). Television news items with mixed and neutral tone are not included in the Figure (results can be requested from authors).

Figure 4 compares the presence of threat frames for the different minority groups in television news coverage. Overall, threat is a common ingredient: half of the news stories contain references to threat. Criminal threat frames are most prevalent, followed by cultural and economic threat frames. However, distinct patterns between the minority groups can be noted. Jews and LGBT are most commonly associated with cultural threat. Eastern Europeans, NorthAfricans and especially Roma, by contrast, are frequently depicted in criminal threat frames. Eastern Europeans and Roma are also depicted in economic threat frames, while North-Africans 
are relatively often associated with cultural threat frames. Longitudinal analysis again demonstrates that these patterns are consistent over time.

Comparing these content data with the prejudice hierarchy among the public already shows large similarities: groups that are depicted in negative news and especially criminal threat frames are also most negatively evaluated by the respondents. Moreover, longitudinal analysis clearly shows that differences in news content in terms of tone and threat frames for the five minority groups are stable and consistent over time.

Figure 4 - News threat frames for minority groups on prime-time television news 2003-2014

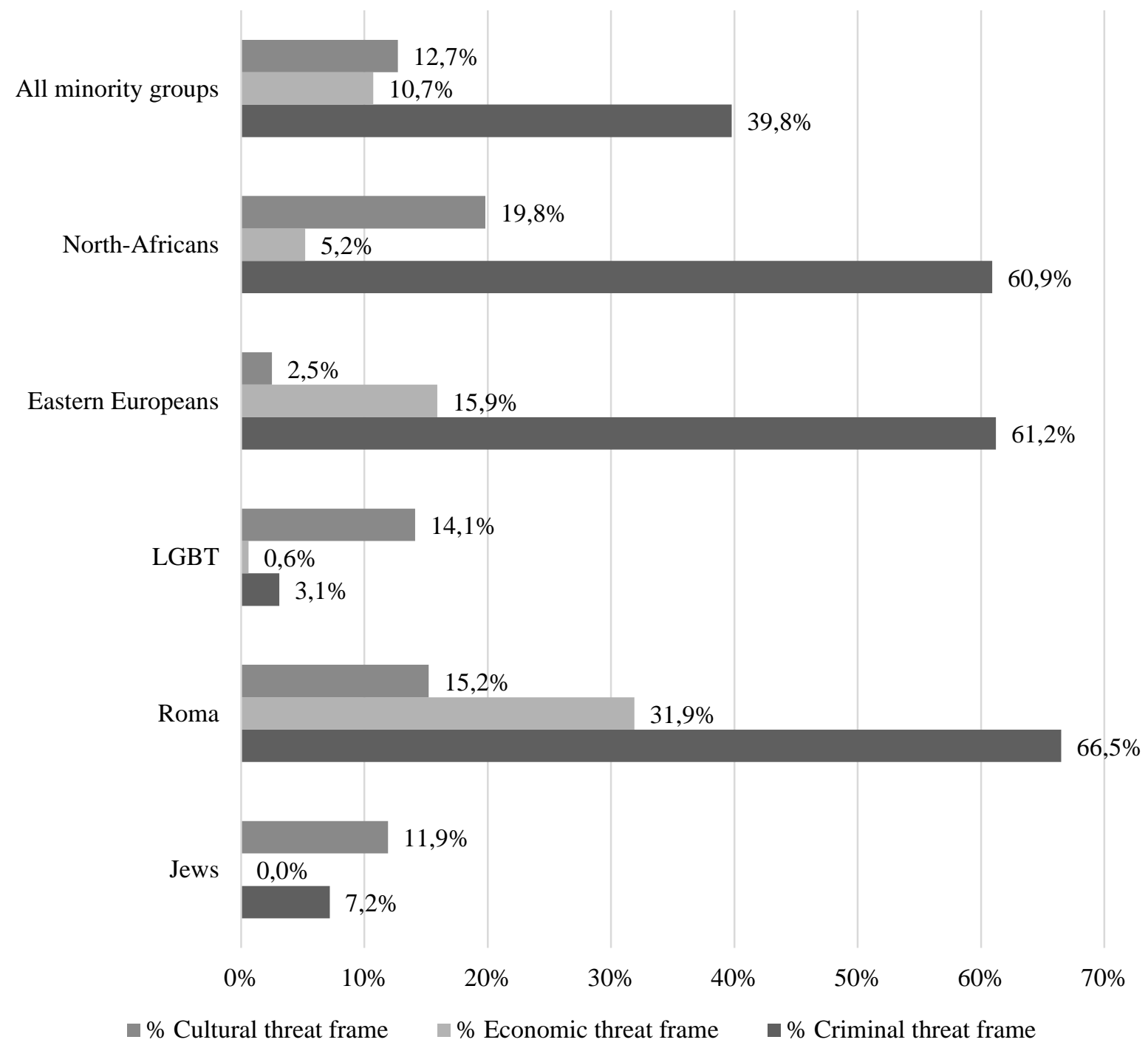

Note: Entries are percentages for news threat frames relative to the number of total news stories about the minority groups on the newscast (2003-2014). Threat frames do not sum to 100\%, as combinations of threat frames in one news items were possible. 
In a next step, we formally tested this preliminary finding by linking news content indicators with survey research via multilevel analysis (Table 1). This way, we can formally test whether news and public opinion have synchronous views on target groups. The baseline intercept model indicates that $29.3 \%$ of the variance in positive feelings can be attributed to differences between individuals and a substantial $69.7 \%$ to differences in ratings between minority groups (Model A). This confirms that individuals differentiate between minority groups, but that target group ratings also share a lot in common, which should be accounted for.

We start by interpreting the level 2 results of Model B-E. Remember that variables at the between-individual level explain differences in average positive feelings across target groups. Women, higher educated, left-wing and younger respondents have more positive feelings toward minority groups in general. The coefficients are easy to interpret: for instance, everything else being equal, women rate all groups on average around four degrees higher than men on a 0-100 degree thermometer. Frequency of consuming television news and other news media are not related to general minority appraisals.

Next, we assess the level 1 results which represent the relationship between television news content and differences between minority evaluations. As hypothesized (H1 and H2), the more often a minority group is portrayed in news items with a positive/negative tone, the more positive/negative the feelings toward that group (Model B \& C), supporting hypothesis 1 and 2. Both relations are quite strong: the difference in feelings between groups that are most positively (LGBT on public news $16.40 \%$ ) and least positively (Roma on commercial news $1.5 \%)$ portrayed, is 41 degrees $([16.40 \%-1.5 \%] * 2.763)^{6}$; the difference in feelings between groups that are most negatively (Jews on commercial news) and least negatively (LGBT on public news) depicted, is 32 degrees ([90.50\% - 52.0\%]* .841). In Model D we added nuance to the tone analysis by assessing whether a negative news story is sufficient, or whether the minority needs to be depicted as cause of the problem in the negative story as well. Both parameters are significant: whether or not the minority group is the cause of negativity, being depicted in a negative news item is still related to less positive feelings toward the group. Finally, minority groups that are more often framed as a criminal threat are rated more negatively than groups portrayed in any other type of threat frame, supporting hypothesis 3.

\footnotetext{
${ }^{6}$ Calculation: For a man, with average age, education level, left-right ideology and TV and other news consumption who watches public news $Y_{\text {homosexuals }}=40.2+(2.763 * 16.4)=85.5$. For person with same characteristics who watches commercial news $Y_{\text {Roma }}=40.2+(2.763 * 1.5)=43.77 ; 85.5-44.3=41.2$.
} 
The effect size of the criminal threat frame was larger than the effect of the economic and cultural threat frame (Model E) (Wald-tests $\mathrm{p}<.05)$. Expressed in terms of relative importance, the maximal difference in feelings between the group that was most often associated with a criminal threat (Roma on commercial news, 71.6\%), economic threat (Roma on public news, $40.8 \%$ ), and cultural threat (North-Africans on public news, 23.6\%) and groups that were least often associated with criminal threat (LGBT on public news, $0.7 \%$ ), economic threat (Jews on public and commercial news, 0.0\%), and cultural threat (Eastern Europeans on commercial news, $1.1 \%$ ) was 31,8 , and 3 degrees respectively.

To test the robustness of our findings, we performed all analyses with news content for a shorter period (2008-2014) and for different age groups. Results were similar: relations between news coverage and prejudice were not specific to the observed news period or age cohort. We opted for the longer period to obtain more variance and sufficiently large sample size, allowing for more reliable results. Moreover, since the longitudinal analysis revealed that patterns over time are stable, we believe this is both empirically and theoretically a sound strategy. 
Table 1 - Multilevel model for television news content and positive feelings toward minority groups

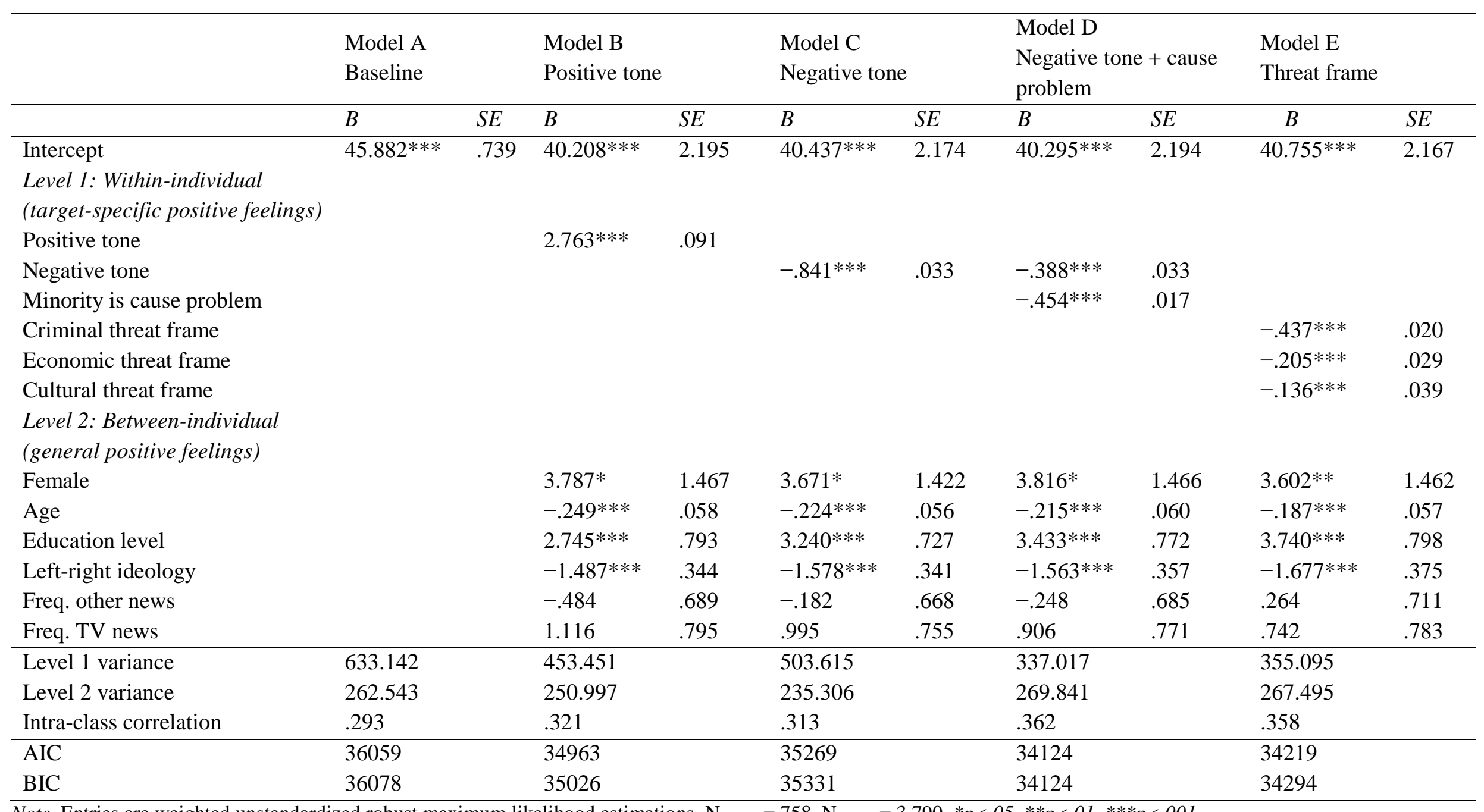

Note. Entries are weighted unstandardized robust maximum likelihood estimations. $\mathrm{N}_{\text {level_} 2}=758, \mathrm{~N}_{\text {level_1 }}=3,790 . * p<.05, * * p<.01, * * * p<.001$ 


\section{Discussion}

The primary aim of this study was to evaluate whether characteristics idiosyncratic to certain target groups relate to differences between evaluations of these groups. We considered television news portrayals of these target groups as a crucial indicator of the intergroup context. We combined television news content indicators (tone and framing) for five minority groups with evaluations of these groups. Three main findings are particularly noteworthy. First, next to a substantial generalized prejudice component, individuals clearly differentiate between minority groups, as some groups are subject to more negative attitudes than others. Second, content analysis revealed a differential news treatment for the five minority groups in line with this hierarchy: the same groups that are most negatively evaluated by the public are generally depicted negatively, problematized and associated with threat frames in the news. Hence, we provide support for Lubbers et al. (1998) suggesting that target-specific news content functions as a contextual factor of target-specific prejudice. Our results show that these representations are consistent over time. Third, combining news content with survey data formally confirmed that attitudes toward different groups follows similar patterns as television news content on these groups.

These results highlight the importance of television news content as part of the specific intergroup context in which individuals' attitudes are formed, adapted or revisited. Television news content greatly diverges in terms of tone and references to threat for minority groups, and these distinct patterns may possibly impact public perceptions of outgroup characteristics. As such, news portrayals of minorities may promote intergroup differences, shape perceived threats and give rise to socially shared representations of these minority groups. However, as we cannot be decisive about the causal mechanism, our results evenly suggest that public opinion can also be very effective in steering news content or that television news is carefully monitoring sensitivities in society. Our cross-sectional data, unfortunately, do not permit us to establish causality. We stress here, however, that we have taken all steps which were possible within the limitations of the data to substantiate causal claims. First, the news content which is linked with the survey data precedes the measurement of attitudes. Second, we have also taken up control variables which are known to correlate with prejudice and news exposure. Finally, our results are in line with past panel studies on media use and prejudice finding evidence for a causal relationship from media to attitudes (Boomgaarden and Vliegenthart, 2009; Schemer, 2012). This, however, does not exclude the possibility of interdependence between news 
content and public opinion. Future studies may therefore want to test the results of our analysis experimentally. Either way, this finding has implications for future research: if news content is conditional on the type of minority group, one should be careful in drawing wide conclusions based on a non-differentiated approach.

Linking the news content analysis with the survey data provided some important insights for prejudice research. First, regarding tone, the overall picture emerging from the television news content is quite pessimistic: positive news is scarce, negative news is dominant, and especially ethnic minorities are depicted in a negative way. Although news generally tends to be negative, what matters here is that the level of this negativity bias in the news diverges between minority groups; a finding which has not yet attracted much scholarly attention in the past (Lubbers et al., 1998). Moreover, from a normative perspective this negativity bias is reason for concern, as the analysis shows that these negative depictions are strongly related to prejudice. Even when minorities are not attributed responsibility, groups that are merely associated with a problem are evaluated more negatively. Still, especially when minorities are portrayed as cause of a problem, associations with negative evaluations were high. This implies that the framing of responsibility is relevant, corroborating Iyengar's (1991) experimental finding that news stories play a large role in the attribution of responsibility and that especially lack of balance of news coverage seems instrumental in stimulating prejudicial beliefs.

Second, an innovating feature of our analysis was the application of pre-defined threat frames to identify which type of threat -cultural, economic or criminal- was more strongly related to negative feelings. In line with our expectations, results show that respondents are especially negative toward groups that are framed through a criminal angle by the news media (Lubbers et al., 1998). This may be because criminal news stories are easy to interpret and can be considered more 'blatant' forms of prejudice (Pettigrew and Meertens, 1995). Moreover, in crime stories responsibility for the problem is usually straightforward, whereas in news stories on cultural and economic threat responsibility attribution is more diffuse. Finally, criminal threat is more prevalent than the other types of threats. Future research should more closely examine the extent to which the composition and formulation of these threat frames differ to pinpoint how the framing exactly relates to attitudes. This finding suggests that criminal threats in Western Europe, also in the news, should not be overlooked when assessing prejudice.

Third, on a more optimistic note, the results do show that positive news stories on minority groups are also associated with more favourable attitudes, which is in line with previous 
evidence (Schemer, 2012). As such, this contradicts the negativity bias which states that especially negative news will have a strong impact on attitudes (Trussler and Soroka, 2014). Still, positive news stories remain scarce. This highlights the potential role of news when considering tolerance toward minority groups, but simultaneously suggests that current policy instruments, such as quota to foster minority visibility by public broadcasters (Van den Bulck and Broos, 2011), may fall short in this regard. Some doubts can be casted about the efficacy of quota, as this study shows that particularly news content greatly matters.

Fourth, the divergent pattern in news content between minorities follows a clear division: North-Africans, Eastern Europeans and Roma are subject to more negative, less positive and more threatening news content than LGBT and Jews. Especially the association of these ethnic minorities with criminal threat is striking. Systematic negative news reports may have serious consequences for intergroup relations with ethnic minorities. It is important to note that this hierarchy in news content of minorities was stable across different news broadcasters and across time. As such, we find clear evidence that news especially highlights perceived (criminal) threats and negative news stories for ethnic minority groups, which in turn correlates with negative evaluations.

Some limitations need to be acknowledged. As was evident from the analysis, news content is dependent upon the minority groups under study. Therefore, future studies should investigate a different set of groups to assess the findings' robustness. Similarly, future research would benefit from including a wider range of contextual prejudice triggers (e.g. intergroup contact, group size, social policy) and assessing them simultaneously. Second, although we had news coverage indicators for a twelve-year period, we could only rely on cross-sectional survey data. Hence, no time-lag fluctuations in intergroup attitudes could be taken into account. The longitudinal analysis of news content, however, revealed that overall patterns in differences between tone and threat frames for the various minority groups were stable and consistent over time. Still, future research would undoubtedly benefit from linking longitudinal content analysis with panel data. Third, while we controlled for consumption of other news sources, we could not control for the content of these sources. It is possible that the same respondent received other information regarding tone and framing, buffering/reinforcing the effects of the television news. Finally, although it was the explicit goal to compare target groups and relate differences in tone and framing to target-specific prejudice, future studies should focus more into-depth on the representation of these single groups as well. 
In summary, we believe that the present study adds to the understanding of the complex relationship between television news content and target-specific prejudice: it suggests that news content on minority groups can indeed be considered a powerful contextual factor reflecting differences between minority appraisals. The similarity between minority group evaluations and news depictions of these groups is remarkable. We conclude that television news content cannot only be linked to overall levels of prejudice, but, in addition, should not be overlooked when considering perceived intergroup differences. This finding implies that studies should be careful when considering minorities as one main group, neglecting intergroup differences, since news maintains a differential treatment for specific groups. 


\section{References}

Allport, G. (1954). The nature of prejudice, Reading, MA: Addison-Wesley.

Atwell Seate, A. \& Mastro, D. (2016). Media's influence on immigration attitudes: An intergroup threat theory approach. Communication Monographs, 83(2), 194-213.

Balmas, M. \& Sheafer, T. (2010). Candidate image in election campaigns: Attribute agenda setting, affective priming, and voting intentions. International Journal of Public Opinion Research, 22(2), 204-228.

Bleich, E., Bloemraad, I. \& de Graauw, E. (2015). Migrants, minorities and the media: Information, representations and participation in the public sphere. Journal of Ethnic and Migration Studies, 41(6), 857-873.

Boomgaarden, H. G. \& Vliegenthart, R. (2009). How news content influences anti-immigration attitudes: Germany, 1993-2005. European Journal of Political Research, 48(4), 516-542.

CIM TV (2014). Top 100 best bekeken programma's 2014 Noord. Available at: http://www.cim.be/downloads.php?type=tv_yearly\&periodicity=yearly\&report=CIM_TV_ Marktaandelen_2012.pdf.

Crandall, C. S. \& Eshleman, A. (2003). A justification-suppression model of the expression and experience of prejudice. Psychological Bulletin, 129(3), 414-446.

Dassonneville, R., Falk Pedersen, E., Grieb, A., \& Hooghe, M. (2014). Belgian Election Panel 2009-2014: Technical report. Leuven.

Dewaele, A., Cox, N., Van den Berghe, W., \& Vincke, J. (2008). The situation concerning homophobia and discrimination on grounds of sexual orientation in Belgium. Antwerp: Steunpunt Gelijkekansenbeleid

De Smedt, J., Wouters, R. \& De Swert, K. (2013). Inter-coder reliability in the TV News Archive. A report on coding issues, countries and actors in Belgian television news. Antwerp: Steunpunt Media.

De Vreese, C. H. (2005). News framing: Theory and typology. Information Design Journal \& Document Design, 13(1), 51-62.

Dixon, T. L. \& Linz, D. (2000). Overrepresentation and underrepresentation of African Americans and Latinos as lawbreakers on television news. Journal of Communication, $50(2), 131-154$.

Duckitt, J. (1992). The social psychology of prejuice, New York, NY: Praeger Publishers.

Entman, R. M. (1993). Framing: Toward clarification of a fractured paradigm. Journal of Communication, 43(4), 51-58.

Eurobarometer (2012). Media use in the European Union. (Standard Eurobarometer 78). 
Available at: http://ec.europa.eu/public_opinion/archives/eb/eb78/eb78_media_en.pdf.

Fiske, S. T., Xu, J., Cuddy, A. C. \& Glick, P. (1999). (Dis)respecting versis (dis)liking: Status and interdependence predict ambivalent stereotypes of competence and warmth. Journal of Social Issues, 55(3), 473-489.

Fryberg, S. A., Stephens, N. M., Covarrubias, R., Markus, H. R., Carter, E. D., Laiduc, G. A., \& Salido, A. J. (2012). How the media frames the immigration debate: The critical role of location and politics. Analyses of Social Issues and Public Policy, 12(1), 96-112.

Gamson, W. A. \& Modigliani, A. (1989). Media discourse and public opinion on nuclear power: A constructionist approach. American Journal of Sociology, 95(1), 1-37.

Hainmueller, J. \& Hiscox, M. J. (2010). Attitudes toward highly skilled and low-skilled immigration: Evidence from a survey experiment. American Political Science Review, 104(1), 61-84.

Hagendoorn, L. (1995). Intergroup biases in multiple group systems: The perception of ethnic hierarchies. European Review of Social Psychology, 6(1), 199-228.

Hallin, D. C. \& Mancini, P. (2004). Comparing media systems. Three models of media and politics. New York: Cambridge University Press.

Havekes, E., Uunk, W. \& Gijsberts, M. (2011). Explaining ethnic outgroup feelings from a multigroup perspective: Similarity or contact opportunity? Social Science Research, 40(6), 1564-1578.

Hopmann, D. N., Vliegenthart, R., De Vreese, C. H., \& Albaek, E. (2010). Effects of election news coverage: How visibility and tone influence party choice. Political Communication, 27(4), 389-405.

Hox, J. (2010). Multilevel analysis. Techniques and applications. New York, NY: Routledge. Iyengar, S. (1991). Is anyone responsible, Chicago: The University of Chicago Press.

Jacobs, L. (forthcoming). Patterns of criminal threat in television news coverage of ethnic minorities in Flanders (2003-2013). Journal of Ethnic and Migration Studies.

Jacobs, L., Meeusen, C., \& D'Haenens, L. (forthcoming). News coverage and attitudes on immigration: Public and commercial television news compared. European Journal of Communication.

Kim, S., Carvalho, J. P., Davis, A. G., \& Mullins, A. M. (2011). The view of the border: News framing of the definition, causes, and solutions to illegal immigration. Mass Communication and Society, 14(3), 292-314.

Krippendorff, K. (2013). Content Analysis: An introduction to its methodology. Third Edition. Thousand Oaks, CA: Sage 
Ljujic, V., Vedder, P., Dekker, H., \& van Geel, M. (2012). Romaphobia: A unique phenomenon?

Romani Studies, 22(2), 141-152.

Lubbers, M., Scheepers, P. \& Wester, F. (1998). Ethnic minorities in Dutch newspapers 1990-

5. Patterns of criminalization and problematization. Gazette, 60(5), 415-431.

Meeusen, C. \& Kern, A. (2016). The effect of contextual factors on the association between different forms of prejudice: a cross-national approach on generalized prejudice. Social Science Research, 55, 1-15.

Morgan, M. \& Shanahan, J. (2010). The State of Cultivation. Journal of Broadcasting \& Electronic Media, 54(2), 337-355.

OECD (2015). International Migration Outlook 2013. Retrieved from http://dx.doi.org/10.1787/migr_outlook-2015-en

Oliver, M. B. \& Armstrong, G. B. (1995). Predictors of viewing and enjoyment of reality-based and fictional crime shows. Journalism \& Mass Communication Quarterly, 72(3), 559-570.

Pettigrew, T. F. \& Meertens, R. W. (1995). Subtle and blatant prejudice in western Europe. European Journal of Social Psychology, 25(1), 57-75.

Riek, B. M., Mania, E. W. \& Gaertner, S. L. (2006). Intergroup threat and outgroup attitudes: A meta-analytic review. Personality and Social Psychology Review, 10(4), 336-353.

Roggeband, C. \& Vliegenthart, R. (2007). Divergent framing: The public debate on migration in the Dutch parliament and media, 1995-2004. West European Politics, 30(3), 524-548.

Schemer, C. (2014). Media effects on racial attitudes: Evidence from a three-wave panel survey in a political campaign. International Journal of Public Opinion Research, 26(4), 531-542.

Schemer, C. (2012). The influence of news media on stereotypic attitudes toward immigrants in a political campaign. Journal of Communication, 62(5), 739-757.

Scheufele, D.A. \& Tewksbury, D., 2007. Framing, agenda setting, and priming: The evolution of three media effects models. Journal of Communication, 57(1), 9-20.

Schlueter, E. \& Davidov, E. (2013). Contextual sources of perceived group threat: Negative immigration-related news reports, immigrant group size and their interaction, Spain 19962007. European Sociological Review, 29(2), 179-191.

Schuck, A. R. T., Vliegenthart, R. \& de Vreese, C. H. (2015). Matching theory and data: Why combining media content with survey data matters. British Journal of Political Science, 46, 205-213.

Sheafer, T. (2007). How to evaluate it: The role of story-evaluative tone in agenda setting and priming. Journal of Communication, 57(1), 21-39. 
Shrum, L.J. \& Bischak, V.D. (2001). Mainstreaming, resonance, and impersonal impact. Human Communication Research, 27(2), 187-215.

Sinardet, D. (2013). How linguistically divided media represent linguistically divisive issues. Belgian TV-Debates on Brussels-Halle-Vilvoorde. Regional \& Federal Studies, 23(3), 311330.

Ter Wal, J., d'Haenens, L., \& Koeman, J. (2005). (Re)presentation of ethnicity in EU and Dutch domestic news: A quantitative analysis. Media, Culture \& Society, 27(6), 937-950.

Trussler, M. \& Soroka, S.N. (2014). Consumer Demand for Cynical and Negative News Frames. The International Journal of Press/Politics, 19(3), 360-379.

Uribe, R. \& Gunter, B. (2007). Are "sensational" news stories more likely to trigger viewers' emotions than non-sensational news stories?: A content analysis of British TV news. European Journal of Criminology, 22(2), 207-228.

Van den Bulck, H. \& Broos, D. (2011). Can a charter make the difference in ethnic minority reporting? A comparative content and production analysis of two Flemish television newscast. Communications, 36(2), 195-216.

van der Linden, M. \& Jacobs, L. (forthcoming). The impact of cultural, economic, and safety issues in Flemish television news coverage (2003-2013) of North African immigrants on perceptions of intergroup threat. Ethnic and Racial Studies.

Van Gorp, B. (2005). Where is the frame? Victims and intruders in the Belgian press coverage of the asylum issue. European Journal of Communication, 20(4), 484-507.

Van Klingeren, M., Boomgaarden, H. G., Vliegenthart, R., \& De Vreese, C. H. (2015). Real world is not enough: The media as an additional source of negative attitudes toward immigration, comparing Denmark and the Netherlands. European Sociological Review, $31(3), 268-283$.

Walgrave, S. \& De Swert, K. (2002). Does news content matter? The contribution of the news media in the making of the issues of the Vlaams Blok. Ethical Perspectives, 9(4), 249-274.

Watson, B. R. \& Riffe, D. (2012). Perceived threat, immigration policy support, and media coverage: hostile media and presumed influence. International Journal of Public Opinion Research, 25(4), 459-479.

Zaller, J. (1992). The nature and origins of mass opinion, Cambridge University Press.

Zhou, Y. \& Moy, P. (2007). Parsing framing processes: The interplay between online public opinion and media coverage. Journal of Communication, 57(1), 79-98. 
Zick, A., Wolf, C., Küpper, B., Davidov, E., Schmidt, P., \& Heitmeyer, W. (2008). The syndrome of group-focused enmity: The interrelation of prejudices tested with multiple cross-sectional and panel data. Journal of Social Issues, 64(2), 363-384. 


\section{Appendix A - Content analysis: Examples}

\begin{tabular}{|c|c|}
\hline Roma & News items \\
\hline Positive tone & $\begin{array}{l}\text { "Exactly one century ago, in a caravan near Charleroi, the gipsy child Django Reinhardt was born. A } \\
\text { phenomenal artist." }\end{array}$ \\
\hline Negative tone + cause & $\begin{array}{l}\text { "In Bergen, in the province of Henegouwen, the police has found a large amount of hand guns, rifles and } \\
\text { mitraillets in a gipsy camp." }\end{array}$ \\
\hline Negative tone + not cause & "The young gipsy who was stabbed last weekend by a group of skinheads has told his story for the first time." \\
\hline Criminal threat frame & "Pickpockets on the run with jewels. Public prosecutor and Department of Justice warn for gipsy gang." \\
\hline Economic threat frame & $\begin{array}{l}\text { "City administration of Ghent asks inhabitants to not offer help to poor Roma families, because this would } \\
\text { encourage more immigration." }\end{array}$ \\
\hline Cultural threat frame & $\begin{array}{l}\text { "The quiet sea-side village Sint-Joris near Nieuwpoort feels overwhelmed by the invasion of evangelic } \\
\text { gipsies." }\end{array}$ \\
\hline LGBT & News items \\
\hline Positive tone & $\begin{array}{l}\text { "In Antwerp, Navigayton has been kicked off, a party marathon for LGBT and their supporters, on and next } \\
\text { to the water." }\end{array}$ \\
\hline Negative tone + cause & "Unsafe sex is a new trend among some seropositive gay men." \\
\hline Negative tone + not cause & "Possibly for the first time in our country, someone was murdered because he was gay." \\
\hline Criminal threat frame & $\begin{array}{l}\text { "Justice in Brussels is investigating the case of a marriage of convenience between a dying gay man and a to } \\
\text { him unknown woman." }\end{array}$ \\
\hline Economic threat frame & "Homosexuals and bi-sexuals, on average, are more educated than hetero people, but they earn less." \\
\hline Cultural threat frame & "There are more and more gay boys that start a career in prostitution." \\
\hline Eastern Europeans & News items \\
\hline Positive tone & "Polish workers are popular in our country." \\
\hline Negative tone + cause & "Eastern European human traffickers sentenced in Dendermonde to prison sentences and fines." \\
\hline Negative tone + not cause & $\begin{array}{l}\text { "Contractor and worker receive a fine for bringing a Polish co-worker who fell off the roof too late to the } \\
\text { hospital." }\end{array}$ \\
\hline Criminal threat frame & "Seven Serbians arrested in Sint-Niklaas, the gang was specialized in stealing luxury cars." \\
\hline Economic threat frame & $\begin{array}{l}\text { "In Brussels construction workers protested against a EU directive which would lead to a flood of cheap } \\
\text { Eastern European workers." }\end{array}$ \\
\hline
\end{tabular}


Cultural threat frame

\section{Jews}

Positive tone

Negative tone + cause

Negative tone + not cause

Criminal threat frame

Economic threat frame

Cultural threat frame

North-Africans

Positive tone

Negative tone + cause

Negative tone + not cause

Criminal threat frame

Economic threat frame

Cultural threat frame
"Minister for Integration, Geert Bourgeois, says migrants from Eastern and Central Europe need to integrate better."

\section{News items}

"Today the Portuguese-Jewish community in Antwerp celebrates the 100th anniversary of the Beth Mosch synagogue."

"Some subsidized Jewish schools have received critical remarks from the school inspectorate."

"After several serious incidents, Minister Dewael, wants to improve the protection of the Jewish community against violence and anti-Semitism."

"The Antwerp diamond centre and several Jewish merchants caused a new scandal due to large amounts of black market money."

/

"There is a judicial dispute about the presence of the yarmulke in the court by the defendants attorneys." News items

"The Flemish Culture Prize for performing arts this year goes to the Flemish-Moroccan choreographer Sidi Larbi Cherkaoui."

"There are tensions in the area surrounding the football stadium of Anderlecht. North-African youth were caught up in a fight with supporters of Anderlecht."

"Flemish family maltreats pregnant Moroccan daughter-in-law."

"Moroccan who was arrested yesterday in Sint-Jans-Molenbeek, was detained by the examining magistrate in Brussels."

"More than half of the Moroccans in our country live under the poverty line."

"At this moment the Crown Court in Brussels is deliberating upon the sentences in the case of an exorcism of a young Moroccan woman by her family." 
Appendix B - Example of data structure combining content analysis and survey data in a two-level multivariate design

\begin{tabular}{|c|c|c|c|c|c|c|c|c|c|c|}
\hline \multicolumn{3}{|c|}{ LEVEL 2: Between-individual } & \multicolumn{8}{|c|}{ LEVEL 1: Within-individual (target-specific) } \\
\hline $\begin{array}{c}\text { ID } \\
\text { respondent }\end{array}$ & $\begin{array}{c}\text { News } \\
\text { broadcast }\end{array}$ & Gender & Minority group & $\begin{array}{c}\text { Positive } \\
\text { feelings }(0-100)\end{array}$ & $\begin{array}{l}\text { \% Positive } \\
\text { tone }\end{array}$ & $\begin{array}{c}\% \text { Negative } \\
\text { tone }\end{array}$ & $\begin{array}{l}\% \text { Negative } \\
\text { tone }+ \text { cause }\end{array}$ & $\begin{array}{l}\% \text { Criminal } \\
\text { threat frame }\end{array}$ & $\begin{array}{l}\text { \% Economic } \\
\text { threat frame }\end{array}$ & $\begin{array}{l}\text { \% Cultural } \\
\text { threat frame }\end{array}$ \\
\hline 1 & Public & Female & Jews & 60 & $7.3 \%$ & $82.8 \%$ & $13.9 \%$ & $4.6 \%$ & $0.0 \%$ & $11.9 \%$ \\
\hline 1 & Public & Female & Roma & 50 & $5.6 \%$ & $77.5 \%$ & $70.4 \%$ & $57.7 \%$ & $40.8 \%$ & $12.7 \%$ \\
\hline 1 & Public & Female & LGBT & 50 & $16.4 \%$ & $52.6 \%$ & $9.2 \%$ & $0.7 \%$ & $1.3 \%$ & $12.5 \%$ \\
\hline 1 & Public & Female & Eastern Europeans & 50 & $8.4 \%$ & $72.1 \%$ & $67.9 \%$ & $62.8 \%$ & $18.6 \%$ & $4.2 \%$ \\
\hline 1 & Public & Female & North-Africans & 75 & $12.5 \%$ & $69.4 \%$ & $58.3 \%$ & $52.8 \%$ & $6.9 \%$ & $23.6 \%$ \\
\hline 2 & Commercial & Male & Jews & 60 & $4.8 \%$ & $90.5 \%$ & $15.9 \%$ & $10.3 \%$ & $0.0 \%$ & $11.9 \%$ \\
\hline 2 & Commercial & Male & Roma & 60 & $1.5 \%$ & $89.6 \%$ & $80.6 \%$ & $71.6 \%$ & $22.4 \%$ & $17.9 \%$ \\
\hline 2 & Commercial & Male & LGBT & 40 & $12.6 \%$ & $57.1 \%$ & $14.3 \%$ & $5.1 \%$ & $0.0 \%$ & $15.4 \%$ \\
\hline 2 & Commercial & Male & Eastern Europeans & 60 & $2.7 \%$ & $82.1 \%$ & $74.4 \%$ & $69.5 \%$ & $13.7 \%$ & $1.1 \%$ \\
\hline 2 & Commercial & Male & North-Africans & 60 & $2.4 \%$ & $90.3 \%$ & $74.2 \%$ & $71.0 \%$ & $3.2 \%$ & $15.3 \%$ \\
\hline 3 & $\mathrm{P} \& \mathrm{C}$ & Male & Jews & 90 & $6.1 \%$ & $86.7 \%$ & $14.9 \%$ & $7.2 \%$ & $0.0 \%$ & $11.9 \%$ \\
\hline 3 & $\mathrm{P} \& \mathrm{C}$ & Male & Roma & 40 & $3.6 \%$ & $83.6 \%$ & $75.5 \%$ & $66.5 \%$ & $31.9 \%$ & $15.2 \%$ \\
\hline 3 & $P \& C$ & Male & LGBT & 20 & $14.5 \%$ & $54.9 \%$ & $11.7 \%$ & $3.1 \%$ & $0.6 \%$ & $14.1 \%$ \\
\hline 3 & $\mathrm{P} \& \mathrm{C}$ & Male & Eastern Europeans & 60 & $5.5 \%$ & $77.1 \%$ & $66.3 \%$ & $61.2 \%$ & $15.9 \%$ & $2.5 \%$ \\
\hline \multirow[t]{2}{*}{3} & $P \& C$ & Male & North-Africans & 50 & $7.5 \%$ & $75.8 \%$ & $69.8 \%$ & $60.9 \%$ & $5.2 \%$ & $19.8 \%$ \\
\hline & $\ldots$ & $\ldots$ & $\ldots$ & $\ldots$ & $\ldots$ & $\ldots$ & $\ldots$ & $\ldots$ & $\ldots$ & $\ldots$ \\
\hline
\end{tabular}

Note. $\mathrm{P} \& \mathrm{C}=$ Public and Commercial 